ADLFI. Archéologie de la France Informations

une revue Gallia

Pays de la Loire | 2008

\title{
Prospection aérienne
}

\section{Patrick Péridy}

Édition électronique
URL : http://journals.openedition.org/adlfi/1972

ISSN : 2114-0502

Éditeur

Ministère de la culture

Référence électronique

Patrick Péridy, "Prospection aérienne », ADLFI. Archéologie de la France - Informations [En ligne], Pays de la Loire, mis en ligne le 01 mars 2008, consulté le 22 avril 2019. URL : http:// journals.openedition.org/adlfi/1972

Ce document a été généré automatiquement le 22 avril 2019

(c) Ministère de la Culture et de la Communication, CNRS 


\section{Prospection aérienne}

\section{Patrick Péridy}

1 Le programme de prospection aérienne 2008 se solde pour la seconde année consécutive par un bilan négatif, qu'il faut imputer une fois encore aux conditions climatiques.

2 Au total, $4 \mathrm{~h} 55$ de survols ont été réalisées. Les renseignements recueillis tout au long de l'été auprès de plusieurs pilotes de la région sur la réponse de la végétation nous ont fait renoncer à reprendre les recherches en juillet et août sur la zone prévue en raison de l'extrême pauvreté des indices observés.

3 Trois missions ont été effectuées, couvrant les zones suivantes :

4 - 13/06/08 : Cholet, Saint-Laurent-sur-Sèvre, Les Herbiers (est), La Chaize le Vicomte, Mareuil-sur-Lay, pourtour nord du Marais poitevin jusqu'à Longeville, Talmont-SaintHilaire, Les Sables-d'Olonne, La Mothe-Achard, La Genétouze, Les Essarts, Saint-Fulgent (2h00).

5 - 18/06/08: Cholet, La Mothe-Achard, Saint-Mathurin, Vairé, vallée du Jaunay depuis l'embouchure jusqu'à Coëx, Challans, La Genétouze (1h20).

6 - 20/06/08 : Cholet, Saint-Laurent-sur-Sèvre, Les Châtelliers-Châteaumur, Montournais, Breuil Barret, Saint-Hilaire-de-Voust, forêt de Vouvant (est), Nieul-sur-l'Autize, Fontenay-le-Comte, pourtour du golfe des Pictons (sauf partie nord), Sainte-Hermine, Monsireigne, Les Epesses (1h35). 
INDEX

Index géographique : Pays de la Loire, Vendée (85), Challans, Cholet, Saint-Laurent-sur-Sèvre, La Chaize-le-Vicomte, Mareuil-sur-Lay, Talmont-Saint-Hilaire, Les Sables-d'Olonne, La MotheAchard, La Genétouze, Les Essarts, Saint-Fulgent, Saint-Mathurin, Vairé, Les ChâtelliersChâteaumur, Montournais, Breuil Barret, Saint-Hilaire-de-Voust, Nieul-sur-l'Autize, Fontenay-leComte, Sainte-Hermine, Monsireigne, Les Epesses

operation Prospection aérienne (PA)

\section{AUTEURS}

\section{PATRICK PÉRIDY}

Association 